\title{
Deveria o Brasil investir em novos grãos para a sua alimentação? A proposta do amaranto (Amaranthus sp.)
}

\author{
Jaime Amaya-Farfan ${ }^{1}$, Roberto Marcílio ${ }^{1}$ e Carlos Roberto Spehar ${ }^{2}$
}

O gênero Amaranthus compreende várias espécies de plantas dicotiledôneas cujas folhas e sementes são regularmente consumidas como alimento em diversos países, entre os quais não se inclui o Brasil. As espécies graníferas se destacam pela vantagem da rapidez de crescimento e produção, possibilitando o cultivo em condições de escassez de umidade na fase reprodutiva. Dadas suas nobres características nutricionais, este grão se apresenta como um alimento naturalmente balanceado, com propriedades de alimento funcional. $\mathrm{O}$ alto valor nutritivo e as características físico-químicas da proteína fazem com que a farinha possa ser utilizada na fortificação de cardápios consumidos pelas populações de baixa e alta renda, sem distinção. As proteínas do grão de amaranto têm ainda alto potencial na elaboração de produtos farináceos isentos de glúten, o que torna este produto de grande importância na ampliação da oferta de alimentos nutritivos para portadores da doença celíaca. Considerando o conjunto de suas propriedades, muito atraentes para a agricultura familiar ou o agronegócio, além do fato da Embrapa ter adaptado cultivares ao cultivo no Cerrado, é difícil entender como o país não aderiu ainda à produção e ao consumo deste produto.

Palavras-chave: agricultura familiar, commodities, alimento saudável, amaranto, caruru

\section{Should Brasil invest in new crop grains? The potential of amaranth (Amaranthus sp.)}

\begin{abstract}
The Amaranthus genus comprises many species of dicotyledoneous plants whose leaves and seeds are often consumed as food in various countries, except in Brazil. From both the agronomic and nutritional standpoints, this cereal has been recognized as advantageous. The grain amaranth species show the advantage of rapid growth and reproduction, resulting in crop yields under low moisture conditions at the reproductive phase. Because of its high nutritional quality grain amaranth is considered as a naturally balanced food bearing additional properties of functional food. Such characteristics would enable nutritionists as well as food processors to utilize this food source to complement traditionally poor diets. The grain proteins and their products make also an excellent food base for nutritious dishes directed to gluten sensitive-individuals. Considering the numerous advantages of this food item, and the fact that Embrapa has now adapted the crop to savannah cultivation, it is difficult to understand why Brazil has not yet engaged in the exploitation of this promising cereal as a means to guarantee food security at the homestead level and enter a new large-scale agribusiness.
\end{abstract}

Keywords: homestead agriculture, commodities, health foods, amaranth grain, caruru

\footnotetext{
${ }^{1}$ Departamento de Alimentos e Nutrição - Faculdade de Engenharia de Alimentos e Núcleo de Estudos e Pesquisas em Alimentação, Universidade Estadual de Campinas, Campinas, SP 13083-862, Brasil

${ }^{2}$ Embrapa, Cerrados, C. Postal 08223, Planaltina, DF 73310-970, Brasil
} 
O Brasil aderiu à produção de soja em escala comercial na década de 60 , para tornar-se o segundo maior produtor mundial no final do século XX. Apesar de contemplar inicialmente um mercado de insumos para ração animal, o advento dos alimentos funcionais impulsionou o consumo da soja como um produto agrícola de relevância direta na alimentação humana, embora nunca alcançando a simpatia do pequeno agricultor, especialmente daquele que subsiste da agricultura familiar. Contrastando com essa situação, se apresenta um quadro bastante interessante, do ponto de vista socioeconômico, que é o da possibilidade do pequeno agricultor conhecer e aderir ao plantio de alguns grãos, típicos da América, que, dadas as suas vantagens agronômicas e nutricionais, podem ser de grande benefício para o homem do campo. Estes grãos, considerados como sendo uma combinação natural de leguminosa com cereal, são adaptáveis a condições marginais de cultivo, como escassez de água na fase final do ciclo, e requerem manejo relativamente simples.

É de conhecimento comum que o consumo do feijão, sem o acompanhamento de um cereal, como arroz, milho ou trigo, resultaria em deficiência nutricional considerável para o homem, sendo passível de rejeição em questão de alguns dias. De igual forma, uma alimentação baseada predominantemente em cereal ou farináceo, também traria conseqüências adversas a uma criança ou um adulto. Dentro do conceito geral de segurança nutricional para o microagricultor, o ideal seria ele próprio manter uma lavoura de subsistência baseada num produto, naturalmente quase completo.

\section{O Amaranto no Mundo e no Brasil}

O amaranto (Amaranthus sp.), uma planta dicotiledônea cujas folhas e sementes são consumidas como alimento em diversas regiões do mundo (Sauer, 1950), é praticamente desconhecido no Brasil. A planta apresenta inflorescências tipo panícula, sendo freqüentemente classificada como 'falso cereal'. Algumas espécies, como $A$. bybridus, $A$. deflexus, $A$. retroflexus, $A$. spinosus, e $A$. viridis $\mathrm{L}$, têm recebido nomes populares como Caruru, Caruru-bravo, Bredo, Carururasteiro, Caruru-roxo, Caruru-branco, Caruru-verde, Caruru-gigante, Caruru-de-espinho (Teutonico e Knorr, 1985). Nas regiões andinas é também conhecido como kiwicha, coime, cuyme, yuyo, achita, trigo-del-inca, entre outros.
As espécies mais estudadas e cultivadas são: o $A$. cruentus (México, África, Caribe, Ásia e América do Sul), A. caudatus (América do Sul), A. bypochondriacus (Índia, México e Estados Unidos) e $A$. tricolor (China e Índia) (Saunders e Becker, 1984; Breene,1991). Seu cultivo se deu desde a antigüidade em várias partes do mundo: da Argentina ao Sudoeste dos Estados Unidos, da Pérsia ao Ceilão, à Índia, ao Himalaia, ao interior da China e à Mongolia e Africa Oriental (Sauer, 1950).

O amaranto tem sido cultivado na América desde antes da chegada dos espanhóis, alcançando seu apogeu nos períodos Maia, Asteca e Inca, e era considerado até então um alimento sagrado. A semente do amaranto, moída e amassada com sangue proveniente de sacrifícios humanos era oferecida às divindades e consumida pelos habitantes em suas cerimônias religiosas. Quando Hernán Cortez conquistou seus territórios em 1519, proibiu essas práticas e o cultivo do amaranto quase desapareceu, embora tenha sido preservado em lugares remotos e montanhosos. Somente em épocas recentes, o amaranto saiu de sua condição obscura, sendo atualmente cultivado no México e América Central e nos territórios andinos da América do Sul (National Research Council, 1984; Yáñez et al., 1994).

Nas últimas décadas, o desenvolvimento comercial do amaranto tem despertado grande interesse em vários países, como EUA, países da União Européia e América Latina (Sanchez-Marroquín, 1983). Segundo esse autor, seu cultivo se desenvolveu principalmente no México, sudoeste dos EUA, sul do Canadá, Guatemala, Peru, Bolívia e norte da Argentina. Várias espécies de amaranto ainda são cultivadas como fonte de grãos no sudeste da Ásia e Manchúria (Hauptli e Jain, 1997).

Por não ser autóctone no Brasil, a planta e o grão têm sido muito pouco estudados e seu consumo chega a ser praticamente desconhecido. Existe, entretanto, um esforço técnico-científico desenvolvido pela EmbrapaCerrados, Planaltina, GO, no sentido de adaptar três espécies graníferas americanas aos solos e ao clima do Cerrado brasileiro.

Durante o processo de seleção, têm-se obtido inúmeros genótipos, dos quais um tornou-se cultivar (BRS Alegria) e outros aguardam o momento oportuno para serem recomendados. Estes se encontram prontos para avaliação tecnológica e nutricional. Os resultados obtidos têm sido encorajadores, pois suas produtividades são altas e até já existe interesse por parte 
de agricultores na sua utilização. Considerando a sua longa trajetória, são abundantes as opções de pratos e receitas disponíveis, inclusive o seu consumo após uma simples tostagem que resulta num produto expandido semelhante à pipoca, snack de milho amplamente aceito pelo consumidor brasileiro. Existem já alguns trabalhos brasileiros que visam à utilização do amaranto e de sua farinha em produtos industrializados (Chavez-Jauregui et al, 2003, Marcílio et al., 2003; Marcílio et al., 2005).

\section{Condições de Cultivo e Características Agronômicas do Amaranto}

De igual importância aos benefícios nutricionais do grão do amaranto, é a resistência desta planta ao estresse hídrico. Diferente da maioria de outras culturas de produtos alimentícios, o amaranto se desenvolve sob condições desfavoráveis aos cereais e às leguminosas, como são as altas planícies da América do Sul. Uma característica agronômica do amaranto, valiosa para o Brasil, é a capacidade da planta se desenvolver e frutificar em ambiente com luminosidade intensa, altas temperaturas $\left(35 \mathrm{a} 45^{\circ} \mathrm{C}\right)$ e restrição hídrica. Isto explica a adaptabilidade das espécies ao Cerrado. Uma outra característica da planta é o seu crescimento rápido. Em três meses, a planta pode atingir cerca de 2 metros de altura, mostrando elevada capacidade de produção de biomassa (Platt e Blasham, 1997). Talvez por causa desta peculiaridade, o amaranto tem registrado rendimentos em massa seca de 4,5 t/ha, em questão de semanas (Teutonico e Knorr, 1985) e rendimentos de sementes de 4 a 6 toneladas/ha (Uzo e Okorie, 1983).

São poucos os testes agronômicos desenvolvidos no Nordeste brasileiro, em função do escasso apoio à pesquisa. Entretanto, dados preliminares indicam que é possível obter um rendimento de $1 \mathrm{t} / \mathrm{ha}$, sob condições de baixa umidade na fase produtiva. Nas regiões onde não há restrição hídrica, rendimentos médios de 3t/ha foram observados.

O amaranto tem uma grande capacidade de aproveitamento de água, luz e nutrientes. Possui raiz profunda que lhe assegura a sobrevivência em períodos de seca, desde que tenha ultrapassado os 30-40 dias após emergência. Caracteriza-se também por sua grande adaptação climática, sendo cultivado desde o nível do mar até altitudes de 3500m (Sumar-Kalinowski, 1986; Guia Rural Abril, 1988). Com relação às propriedades fito-sanitárias do amaranto, Bresler et al. (1998) relataram que o grão não é bom substrato para fungos toxigênicos, o que faz deste um produto pouco susceptível à contaminação por aflatoxinas e zearalenona, ao contrário do que ocorre com os cereais e as leguminosas.

\section{Composição, Valor Nutritivo e Funcional}

Apesar de seu consumo estar restrito a alguns países e ainda, dentro de certas regiões, o potencial do amaranto como fonte de nutrientes é bastante alto. $\mathrm{O}$ interesse no seu aproveitamento é reconhecido por organismos internacionais, sendo para tanto necessário que sejam criados produtos de aceitabilidade geral, que viabilizem sua incorporação à alimentação humana, e a de seus resíduos a rações animais.

$\mathrm{O}$ interesse despertado em tempos recentes por esta planta na Europa, Estados Unidos, Canadá e Japão, pode ser atribuído às suas propriedades nutricionais e de saúde.

Os grãos de amaranto chamam a atenção pelo seu conteúdo relativamente alto de proteínas $(\sim 15 \%)$, gorduras e minerais, especialmente quando comparado aos cereais. A proteína é considerada de alta qualidade biológica devido ao seu conteúdo em lisina e outros aminoácidos essenciais. Esses fatores situam o amaranto acima dos cereais em termos de potencial nutricional (Bressani, 1988; Breene, 1991). A composição mostra que $5 \%$ da proteína é lisina (podendo chegar até 6,9) e $4,4 \%$ são aminoácidos sulfurados. Estes dois grupos de aminoácidos representam o que há de mais limitante em quase todos os grãos (Teutonico \& Knorr, 1985). Além deste fato, a proteína apresenta um alto valor biológico.

Saunders \& Becker (1984), constataram que o conteúdo percentual de proteína $(14,9)$, gordura $(6,98)$ e fibra $(4,5)$ do amaranto eram superiores aos dos cereais comuns, como trigo (proteína 12,3, gordura 1,8, fibra 2,3), milho (proteína 8,9, gordura 3,9, fibra 2,0), arroz integral (proteína 7,5, gordura 1,9, fibra 0,9 ) e aveia (proteína 16,1, gordura 6,4, fibra 1,9). Análise das gorduras indica que os ácidos oléico mais linoléico e o ácido esteárico constituem cerca de 70 e $20 \%$ da gordura total, respectivamente (Yañez et al., 1994). Nessa mesma fração, encontra-se um precursor do esqualeno.

Da parte verde podem-se utilizar as folhas tenras, usadas como saladas, concentrados protéicos, substituto do espinafre, sopas, recheios, produtos 
instantâneos e alimentos infantis, e os talos como suplemento mineral e forragem. As sementes são empregadas em sopas, ensopados, confeitarias, recheios e, sob a forma de farinha, em mingaus, panquecas, pão, "tortilhas" e outros, inclusive em bebida semelhante ao leite (Wheeler et. al., 1981; Cheeke \& Bronson, 1980).

Por suas características nutricionais, a farinha de amaranto desponta como um ingrediente alimentar altamente desejável para consumo como alimento de subsistência (base alimentar) ou para o enriquecimento da dieta de muitas comunidades no Terceiro Mundo. $O$ alto valor nutritivo da proteína faz com que o grão de amaranto seja aplicável, tanto na fortificação de farinhas de trigo, milho e tubérculos, como na elaboração de produtos farináceos isentos de glúten. Esta última aplicação também seria da maior importância visando ampliar a oferta de alimentos altamente nutritivos para celíacos.

Estes setores da população geralmente padecem de vários graus de desnutrição, ocasionados pela baixa capacidade de absorção de nutrientes e aumento do risco de infecções e até câncer, eventos decorrentes da erosão da mucosa intestinal (Dieterich et al., 1997).

O grão de amaranto oferece ainda vantagens para o desenvolvimento de produtos alimentícios nãoalergênicos, sendo de possível aplicação no combate às alergias (Hibi et al, 2003), com potencial estimado em 10 ou mais milhões de consumidores brasileiros, sem considerar o consumidor comum que busca orientação nutricional. Relatos recentes indicam que o amaranto pode ser considerado como alimento funcional devido a seu alto conteúdo nos fitosteróis: â-sitosterol, campesterol e stigmasterol (Marcone et al., 2003), o que poderia explicar em parte as alegações de ser um alimento controlador da hipercolesterolemia (Plate \& Areas, 2002).

\section{Composição Protéica e Aminoacídica}

A composição da proteína, em relação ao perfil de aminoácidos, é bastante variada entre as diversas espécies de amaranto. Um fator comum, entre todas as espécies estudadas, porém, é o alto conteúdo de lisina e aminoácidos sulfurados, assim como também o baixo conteúdo de treonina, leucina, valina e isoleucina, quando comparada com o perfil da FAO (1985).
Segundo Gorinstein et al. (1998), as três espécies mais cultivadas e estudadas do amaranto apresentam uma variação no seu teor protéico. $\mathrm{O}$ teor protéico na espécie cruentus, varia de 13,2 a 18,2\%, enquanto nas espécies hypochondriacus e caudatus, o teor médio está em torno de $17,9 \%$.

Os aminoácidos limitantes nas leguminosas, na carne e no leite são os sulfurados, enquanto que nos cereais, são lisina e treonina. A proteína do amaranto possui um balanço de aminoácidos excepcionalmente atraente para a nutrição humana, devido aos seus altos níveis de lisina e metionina. Este fato faz com que o grão de amaranto seja considerado como uma mistura natural de cereal com leguminosa, pois não há necessidade de que o aminoácido mais limitante do cereal, a lisina, seja fornecido por uma leguminosa. Por sua vez, e longe da limitância primária dos cereais ou das leguminosas, os aminoácidos limitantes no amaranto são: a leucina, seguida da treonina (Sauders $\&$ Becker, 1984). Isto representa uma outra vantagem para o amaranto, já que a leucina está presente em excesso na maioria dos alimentos.

Assim como a quinoa, a farinha integral de amaranto apresenta um alto valor calórico (413,8kcal/ $100 \mathrm{~g})$. O valor calórico encontrado para o amaranto é mais alto do que nos cereais conhecidos. Este grão sobressai também como fonte de energia importante para os habitantes de regiões montanhosas, cujas necessidades calóricas são fornecidas pelo amaranto, pela quinoa e pela batata, especialmente onde outras fontes de energia e proteína animal são escassas (Gonzáles et al., 1989). Outra propriedade importante, que distingue a farinha de amaranto da de outros grãos é a de não perder a sua característica de alto teor protéico e perfil aminoacídico de alta qualidade após o refino, fenômeno de ocorrência comum com os cereais (Marcílio et al., 2003).

\section{Vitaminas e Minerais}

As Tabelas 1 e 2 apresentam os valores encontrados por diferentes autores para vitaminas e minerais. Vitamina C e provitamina A estão presentes em níveis nutricionalmente significativos (Tabela 1), média de $420 \mathrm{mg} / \mathrm{kg}$ de vit. C e $250 \mathrm{mg} / \mathrm{kg}$ de bcaroteno (Wills et. al., 1984). Minerais como potássio, ferro, magnésio e cálcio existem também em concentrações expressivas, com valores médios de $287 \mathrm{mg} / \mathrm{kg}$ para ferro e $2,1 \%$ de cálcio (matéria seca). 
O amaranto pode satisfazer as necessidades da maioria das vitaminas recomendadas pelo "Committee on Dietary Allowances" (IOM, 2000). Em geral, as quantidades de minerais na semente de amaranto também são suficientes para satisfazer as recomendações nutricionais.

O amaranto contém mais cálcio, ferro e fósforo do que os cereais comuns (centeio, arroz, trigo, etc.). Além disso, este grão não contém saponinas e os conteúdos de ácido fítico, taninos e oxalatos são baixos.

\section{Fatores Antinutricionais do Amaranto}

De acordo com Lorenz e Wright (1984), a quantidade de fitatos encontrada no amaranto $(0.52$ $0.61 \%$ ) é menor do que no milho $(0.9 \%)$ e no trigo durum (0.98-1.43\%), mas maior do que a encontrada no arroz branco $(0.10-0.14 \%)$.

Os taninos, compostos fenólicos considerados antigamente de forma sumária como antinutricionais, estão presentes no amaranto em quantidades moderadas.

Tabela 1. Composição nutricional das espécies do gênero Amaranthus.

\begin{tabular}{|c|c|c|c|c|c|}
\hline Análises & A. cruentus & A. edulis & A. bypochondriacus & A. bybridus & A. caudatus \\
\hline Mistura (\%) & $6.23-6.71$ & $9.55-11.6$ & 11.1 & 9.2 & 9.3 \\
\hline Proteína (Nõ6,25) & $13.2-17.6$ & $15.80^{b}-16.5$ & $13.9-17.3$ & $14.0-17.2$ & 12.5 \\
\hline Lipídios totais $^{\mathrm{c}}$ & $0.3-8.1$ & $6.9-8.1$ & $4.8-7.7$ & $6.2-6.4$ & 7.1 \\
\hline Fibra bruta ${ }^{c}$ & $3.4-5.3$ & $3.2-5.8$ & - & 8.1 & 7.2 \\
\hline Cinzas $^{c}$ & $2.8-3.6$ & $3.2-4.4$ & $3.3-4.1$ & 4.2 & 2.1 \\
\hline $\mathrm{Na}^{\mathrm{d}}$ & 31 & 37 & $6.7-10.0$ & - & - \\
\hline $\mathrm{K}^{\mathrm{d}}$ & 290 & 580 & - & - & \\
\hline $\mathrm{Ca}^{\mathrm{d}}$ & 175 & 36 & $137-167$ & - & - \\
\hline $\mathrm{Mg}^{\mathrm{d}}$ & 244 & - & $292-363$ & _ & - \\
\hline $\mathrm{Fe}^{\mathrm{d}}$ & 17.4 & 3.1 & $9.1-21.7$ & - & - \\
\hline $\mathrm{Zn}^{\mathrm{d}}$ & 3.7 & - & $3.6-3.9$ & - & - \\
\hline $\mathrm{Cu}^{\mathrm{d}}$ & 1.2 & - & $0.6-0.8$ & - & - \\
\hline $\mathrm{Mn}^{\mathrm{d}}$ & 4.6 & - & $1.9-2.9$ & - & - \\
\hline Riboflavina $^{\mathrm{d}}$ & $0.19-0.23$ & - & 0.29 & - & - \\
\hline Niacina $^{\mathrm{d}}$ & $1.17-1.45$ & - & 1.15 & - & - \\
\hline Ácido ascórbico ${ }^{\mathrm{d}}$ & 4.5 & - & 2.8 & - & - \\
\hline Tiamina $^{\mathrm{d}}$ & $0.07-0.1$ & - & 0.25 & - & - \\
\hline Fitato (\%) & $0.50-0.58\left(2.20^{e}\right)$ & $3.39^{\mathrm{e}}$ & $0.54-0.62$ & 0.55 & - \\
\hline $\begin{array}{l}\text { Taninos } \\
\text { (equiv. catequinas \%) }\end{array}$ & $0.043-0.13$ & 0.22 & $0.054-0.065$ & 0.12 & - \\
\hline
\end{tabular}

${ }^{a}$ Fonte: Afolabi et al (1981), Becker et al (1981), Carlsson (1980), Conner et. al (1980), Lorenz and Wright (1984), Martin and Telek (1979), Sánhez-Marroquín (1980), Schmidt (1977), Uzo e Okorie (1983).

${ }^{\text {b }} \mathrm{N}$ o 5,85

c \% matéria seca $(\% \mathrm{dm})$

${ }^{\mathrm{d}} \mathrm{mg} / 100 \mathrm{~g}$ de matéria seca

${ }^{\mathrm{e}} \mathrm{mmole} / 100 \mathrm{~g}$ 
A proposta do amaranto (Amaranthus sp.), Amaya-Farfan et al.

Tabela 2. Comparação entre os níveis de cálcio, ferro e fósforo do amaranto com outros cereais.

\begin{tabular}{lccc}
\hline Grão & Cálcio $(\mathrm{mg} / 100 \mathrm{~g})$ & Ferro $(\mathrm{mg} / 100 \mathrm{~g})$ & Fósforo $(\mathrm{mg} / 100 \mathrm{~g})$ \\
\hline Amaranto & 162 & 10.0 & 455 \\
Centeio & 38 & 2.6 & 376 \\
Milho & 33 & 2.8 & 282 \\
Trigo & 41 & 3.3 & 372 \\
Arroz & 32 & 1.6 & 360 \\
Leite & 118 & Traços & 93 \\
\hline
\end{tabular}

Fonte: Institute of Food Technologists

Menores quantidades de taninos têm sido observadas em várias espécies de amaranto, em relação aos níveis em grãos de outros cereais (Becker et. al., 1981). Ocorrem variações nos níveis, entretanto, de acordo com a espécie de amaranto, como visto na Tabela 1. A quantidade de tanino no $A$. cruentus, por exemplo, varia de 0.043 a $0.13 \%$, no $A$. hypochondriacus, de 0,054 a $0,065 \%$, no $A$. edulis é de $0,22 \%$, e no $A$. bybridus, de $0.12 \%$. Os taninos estão concentrados na parte externa da semente, e quanto mais escura esta, maior é seu conteúdo nestes compostos (Suarez \& Engleman,1980).

Yáñez et al. (1994) relatam que o $A$. cruentus, diferentemente da quinoa, não contém saponina, composto que confere a esta última propriedade sensorial característica. Outros fatores antinutricionais, como o fator antitríptico e hemaglutininas (lectinas), aparentemente estão presentes em baixas concentrações no grão de amaranto, o mesmo acontecendo com nitritos e oxalatos.

Vários investigadores têm encontrado níveis de nitrato incomumente elevados em folhas de amaranto, semelhantes aos do espinafre, mas somente em casos de alta fertilização com nitrogênio ou estresse hídrico exacerbado da planta (Gilbert et al, 1946; Maynard et al., 1976; Lorenz, 1978).

Der Manderosian et al. (1979) mediram os teores de nitrato produzidos em duas épocas do ano em uma série de variedades de amaranto, e verificaram que a média dos níveis de nitrato na planta permanecia relativamente constante. Eles concluíram que os níveis presentes não são significativos para prejudicar a qualidade nutricional. Variações dentro das espécies são da mesma ordem das variações sazonais.
Em adição aos nitratos, grande quantidade de oxalatos é também encontrada em vegetais folhosos verdes. Os oxalatos da dieta têm a capacidade de ligarse aos cátions divalentes, particularmente cálcio e zinco, fazendo com que estes se tornem indisponíveis para o metabolismo. Quando em excesso, os oxalatos também contribuem para a formação de cálculos renais.

Oxalatos totais e solúveis em folhas foram determinados por estudos de Der Manderosian et al. (1979). Os oxalatos solúveis de verduras cozidas são normalmente descartados com a água de cocção. $\mathrm{O}$ espinafre e o cacto contêm mais oxalatos totais do que o amaranto, mas as proporções de oxalatos solúveis são similares. Esses autores acreditam que os níveis de nitrato e oxalato normalmente encontrados no amaranto granífero não representam um risco para a saúde do consumidor. Por outro lado, trabalhando com a folha de amaranto não granífero (A. gangeticus), Larsen et al. (1989) concluíram que o consumo de folhas preparadas da forma tradicional na África ocidental (cozido e seco ao sol) inibe a absorção e deposição óssea de cálcio em ratos jovens. Vityakon e Standal (1989) relataram que a espécie gangenticus contém aprox. $90 \mathrm{~g}$ de oxalato total por $\mathrm{kg}$ de folha seca. A sugestão dos autores é de que seja descartada a água de cocção, reduzindo o oxalato total para a metade. De toda forma, as folhas tenras possuem menor acúmulo de oxalato do que as maduras.

\section{Fibra Alimentar}

Entre os grãos integrais, as leguminosas, aveia $\mathrm{e}$ cevada contêm um equilíbrio de fibras solúveis e insolúveis. Os cereais, de modo geral, apresentam maior teor de fibras insolúveis do que de solúveis, enquanto 
que as frutas possuem altos teores de fibras solúveis e baixos teores de insolúveis. $\mathrm{O}$ amaranto é um cereal que se apresenta como excelente fonte de fibra insolúvel, principalmente de lignina e celulose. Segundo Becker \& Saunders (1994), o teor total de fibra encontrada no amaranto é superior ao dos cereais comuns.

Estudos de Danz \& Lupton (1992) relataram que o amaranto produz efeitos benéficos na redução dos níveis de lípides séricos, embora menos pronunciados do que no caso da aveia. Visto que a concentração do precursor de esqualeno é alta, tem se pensado que o amaranto reduz o nível de lípides através da inibição da HMG-CoA redutase, enzima presente no fígado que regula a biossíntese de colesterol.

Estes mesmos autores demonstraram que dietas elaboradas com pectina, farelo de aveia e amaranto, separadamente, resultaram em menores teores de colesterol sérico total do que o grupo controle de animais que receberam uma dieta isenta de fibra ou suplementada com celulose. As fibras não apresentaram efeito sobre os níveis de triacilgliceróis no soro. Quando os animais foram alimentados com dietas elaboradas com pectina e farelo de aveia, separadamente, mostraram menores quantidades de colesterol no fígado do que o grupo controle, que recebera uma dieta isenta de fibras. Por sua vez, o grupo que recebeu celulose como fonte de fibras, mostrou níveis mais elevados. $\mathrm{O}$ amaranto apresentou níveis próximos aos do farelo de aveia.

\section{Outras aplicações do Amaranto}

Do ponto de vista alimentar, amaranto é um produto ideal para pessoas portadoras da doença celíaca, por não possuir glúten e proteger o intestino (Marcílio et al, 2005.). Além disso faltam opções nutritivas para esta fração da população. Pelo fato de não possuir glúten, a farinha do grão não se presta naturalmente para a fabricação de pão, como é comumente conhecido. Entretanto, o amido tem sido estudado e foi verificado possuir características industrialmente interessantes.

Singhal e Kulkarni (1990 a, b) encontraram que o amido de amaranto é superior ao de milho quando utilizado em temperos para salada e em aplicações para engrossamento, onde se espera alcançar máxima viscosidade. Pesquisadores anteriores apontaram para uma propriedade inusual do amido de amaranto nativo de exibir resistência ao congelamento e descongelamento. Este amido é conhecido por ser relativamente impérvio a alguns tipos de tratamento térmico, embora as condições ácidas possam limitar a sua estabilidade.

Devido à sua característica de alimento naturalmente balanceado, o amaranto pode ser utilizado sem acompanhamento, tanto como grão inteiro, como farinha integral, ou em combinação com outros cereais. Em combinação com farinha de trigo, "noodles", "cookies", batatas, mandioca ou milho, pães e bolos de alto teor protéico podem ser elaborados, melhorando o valor nutricional do produto ou prato final. Como já foi sugerido, o amaranto pode ser usado para fortificar o trigo e outros produtos de cereais em níveis de até $15 \%$ sem com isso alterar significativamente as propriedades funcionais tecnológicas da massa ou de seus produtos. Embora o grão se preste naturalmente para a elaboração de produtos expandidos, tipo pipoca, a extrusão industrial do grão de amaranto integral pode resultar em importantes aplicações.

O alto valor nutritivo de sua proteína faz com que o grão de amaranto seja aplicável, tanto na fortificação de farinhas de trigo, milho e tubérculos, como na elaboração de produtos farináceos isentos de glúten. Esta última aplicação tem a sua importância na ampliação da oferta de alimentos para celíacos.

No estado jovem, as plantas são tradicionalmente consumidas como hortaliças, sendo por essa razão atribuída ao amaranto total a propriedade de ser nutricionalmente mais útil ao homem do que os cereais.

Quanto ao uso na alimentação, toda a parte aérea da planta adulta vem sendo utilizada de forma tradicional. Da parte verde podem-se citar: as folhas tenras, usadas como saladas, concentrados protéicos, substituto do espinafre, sopas, recheios, produtos instantâneos e alimentos infantis. Dos talos, podem ser obtidos suplementos minerais e forragem.

\section{Conclusão}

A adaptação do grão de amaranto (Amaranthus sp.) aos solos e climas brasileiros pela Embrapa já é um fato consumado e abre as portas à popularização e utilização desta semente altamente nutritiva, até agora desconhecida no Brasil como fonte alimentar. Pelas 
suas características composicionais, seria duplamente benéfico para as populações rurais conhecer e produzir o amaranteiro como cultura de subsistência e, mesmo para o agricultor em escala comercial, levando em conta a existência de um mercado em expansão baseado em: 1) explosão da procura pelos alimentos funcionais; 2) possibilidade real do amaranto e seus produtos serem passíveis de industrialização; e 3) potencial desta matéria-prima de alto valor nutricional de servir na diversificação e enriquecimento da alimentação de populações que devem excluir o glúten da sua dieta.

Propõe-se que setores competentes do Governo se informem sobre as propriedades agronômicas e nutricionais do amaranto e incentivem seu plantio e consumo a fim de garantir um melhor aproveitamento dos investimentos em alimentação e saúde da população, especialmente aquela que depende da agricultura familiar. A exploração das formas integral ou refinada do grão tem suficiente potencial para converter este produto em uma commodity de significância para o país.

\section{Referências Bibliográficas}

AFOLABI, A. O.; OKE, O. L.; Umoh I. B. Preliminary studies on the nutritive value of some cereal-like grains. Nutrition Reports International, v. 24, p. 389-, 1981.

BECKER, R. ; Saunders, R. M. Amaranthus: A potential food and feed resource. Advances in Cereal Science and Technology, v. 6, p. 257-396, 1984.

BECKER, R. et al. A compositional study of Amaranth grain. Journal of Food Science, v. 46, p. 1175-1180, 1981.

BREENE, W. M. Food uses of grain amaranth. Cereal Foods World, St. Paul, v. 36, n.5, p. 426-429, 1991.

BRESLER, G. et al. Amaranth grain as substrate for aflatoxin and zearalenone production at different water activity levels. International Journal of Food Microbiology, v. 42, n. 1-2, p. 57-61, 1998.

BRESSANI, R. Amaranth. The nutritive value and potential uses of the grain and by-products. Food and Nutrition Bulletin, Tokyo, v. 10, n. 2, p. 49-59, 1988.

CARLSSON, R. Quantity and quality of amaranth grain from plants in temperate, cold and hot and subtropical climates. A review. In: Amaranth Conference, 2, Proceedings of the $2^{\text {nd }}$ Amaranth Conference, Emmaus : Rodale Press, p.48, 1980.

CHAVEZ-JAUREGUI, R. N. Acceptability of snacks produced by the extrusion of amaranth and blends of chickpea and bovine lung. International Journal of Food Science and Technology, v. 38, n. 7, p. 795-798, 2003.

CHEEKE, P. R. ; BRONSON, J. Feeding trials with amaranthus grain, forage and leaf protein concentrates. In: Amaranth Conference, 2, Proceedings of the Second Amaranth Conference, Emmaus : Rodale Press, p. 5-11, 1980.

CONNOR, J. K. et al Amaranthus edulis. An ancient food source re-examined. Australian Journal of Experimental Animal Husbandry, v. 20, p. 156, 1980.

DANZ, R. A.; LUPTON, J .R. Physiological Effects of Dietary Amaranth (Amaranthus cruentus) on Rats. Cereal Foods World, v. 37, n. 7, p. 489-494, 1992.

DER MANDEROSIAN, A.D. et al. Nitrate and oxalate content of vegetable amaranth. In: Amaranth Conference, 2., 1979, Proceedings $2^{\text {nd }}$ Amaranth Conference, 1979, p. 31-41.

DIETERICH, W. et al. , Identification of tissue transglutaminase as the auto antigen of celiac disease. Nature Medicine, v. 3, p. 797-801, 1997.

EARLY, D; EARLY, J. C.. Transferencia de tecnología indígena para la preparación de la Kiwicha (Amaranthus). Primera parte. El Amaranto y su Potencial. Boletín, Guatemala, v. 4, p. 8-12, 1987.

FAO. Necesidades de Energía y Proteínas: Relatório da Reunião Consultiva Conjunta de Especialistas FAO-OMS-UNU, Food and Agricultural Organization of the United Nations. Genebra, 1985.

GILBERT, G. S. et al. Nitrate accumulation in cultivated plants and weeds. Bulletin 277. Univ. Wyoming (Laramie) Agric. Experiment Station, 1946.

GONZÁLES J. A. Quantitative determinations of chemical compounds with nutritional value from Inca crops: Chenopodium quinoa ("quinoa"). Plant Foods for Human Nutrition, Lincoln, v. 39, n. 4, p. 331-337, 1989. 
GORINSTEIN, S. Computation analysis of amino acid reside sequences of amaranth and some other proteins. Bioscience Biotechnology and Biochemistry, v. 62, n. 10, 1845-1851, 1998.

HAUPTLI, H. e JAIN, S. Amaranth and meadowfoam: two new crops? California Agriculture, Berkeley, v. 31, n. 9, p. 6-7, 1977.

HIBI, M. et al. Amaranth grain inhibits antigenspecific IgE production through augmentation of IFN-g response in vivo and in vitro. Citotechnology, v. 43, p. 33-40, 2003.

LARSEN, T. et al... The leafy vegetable amaranth (Amaranthus gangeticus) is a potent inhibitor of calcium availability and retention in rice-based diets. British Journal of Nutrition, v. 90, n.3, p. 521-527, Sep 2003.

LORENZ, K. ; WRIGHT, B. Phytate and tannin content of Amaranth. Food Chemistry, v. 14, p. 2734, 1984.

LORENZ, O. A. Potential nitrate levels in edible plants. In: Nielson D. R. ; Mac Donald, J. G. (eds.). Nitrogen in the Environment. Vol. 2. New York : Academic Press, 1978. p. 201-219.

MARCÍLIO, R. et al. Fracionamento do grão de amaranto (A. cruentus) brasileiro e suas características composicionais Ciência e Tecnologia de Alimentos, v. 23, n. 3, p. 511-516, 2003.

MARCÍlIO, R. ; AMAYA-FARFAN, J. ; SILVA, M. A. A. P. Performance da farinha de amaranto na elaboração de biscoito tipo "cookie" para celíacos. Brazilian Journal of Food Technology (aceito), 2005.

MARCONE, M. F.; KAKUDA, Y.; YADA, R. Y. Amaranth as a rich dietary source of beta-sitosterol and other phytosterols. Plant Foods for Human Nutrition, v. 58, n. 3, p. 207-211, 2003.

MARTIN, F. W.; TELLEK, L. Amaranth and Celosia In: Vegetables for the hot, humid tropics.. New Orleans, LA : US Department of Agriculture, 1979. Part 6.

MAYNARD, D. Net al. Nitrate accumulation in vegetables. Advances in Agronomy. V. 28, p.71-118, 1976.
National Research Council. Amaranth: modern prospects for an ancient crop. Washington: National Academy Press, 1984. 81p.

PLATE, A.Y. A. ; AREAS, J. A. G. Cholesterollowering effect of extruded amaranth (Amaranthus caudatus L.) in hypercholesterolemic rabbits. Food Chemistry, v. 76, n.1, p. 1-6, 2002.

PLATT, S. G.; BLASHAM, J. A. Photosynthesis and increased production of protein. In: FRIEDMAN, M.( ed.) Nutritional improvement of food and feed proteins. New York: Plenum Press, 1977. p.195-247

SÁNCHEZ-MARROQUÍN, A. Dos cultivos olvidados de importancia agroindustrial: el amaranto y la quinoa. Archivos Latinoamericanos de Nutrición, Guatemala City, v. 23, n. 1, p. 11-32, 1983.

SAUER, J. D. The grain amaranthus; a survey of their history and classification. Annals of Missouri Botanic Garden, St. Louis, v. 37, p. 561-618, 1950.

SAUNDERS, R. M.; BECKER, R. Amaranthus: a potencial food and feed resource. Advances in Cereal Science and Technology, St. Paul, v. 6, p. 357-396, 1984.

SUAREZ, G. R.; ENGLEMAN, E. M. Tannin deposition in the testa of Amaranthus bypochondriacus L. (Alegria). Agronomia , v. 42, p. 35-39, 1980.

SUMAR-KALINOWSKI L. Amaranthus sp. E1 pequeño gigante., Relatório UNICEF. Cusco, 1986. p1-24.

TEUTONICO, R. A.; KNORR, D. Amaranth; composition, properties and aplications of a rediscovered crop. Food Technology, Chicago, v. 39, n. 4, p. 49-59, 1985.

US National Academy of Sciences. Institute of Medicine. Dietary Reference Intakes. 2000.

USO, J. O.; OKORIE, A. U. Amaranthus hybridus; a potential grain crop for West Africa. Nutrition Reports International, v. 27, n. 3, p. 519-524, 1983.

VITYAKON, P.; STANDAL, B. R. Oxalate in vegetable amaranth (amaranthus-gangeticus) - forms, contents, and their possible implications for human health. Journal of the Science of Food and 
Agriculture, v. 48, n.4, p. 469-474, 1989.

WHEELER, E. L. et al. A composition study of amaranth grain. Journal of Food Science, Chicago, v. 46, p. 1175-1180, 1981.
YÁNEZ, E. et al. Caracterización química y nutricional del amaranto (Amaranthus cruentus). Archivos Latinoamericanos de Nutrición, Caracas, v. 44, n. 1, p. 57-62, 1994. 